\title{
Cervical Cytology: A Review of 597 Cases in a Tertiary Health Centre in Nigeria
}

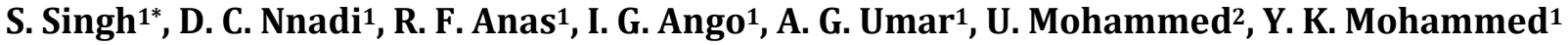 \\ ${ }^{1}$ Department of Obstetrics and Gynaecology, Usmanu Danfodiyo University Teaching Hospital, Sokoto, Nigeria \\ ${ }^{2}$ Department of Histopathology, Usmanu Danfodiyo University Teaching Hospital, Sokoto, Nigeria \\ Email: *swasingh@yahoo.co.in
}

How to cite this paper: Singh, S., Nnadi, D.C., Anas, R.F., Ango, I.G., Umar, A.G., Mohammed, U. and Mohammed, Y.K. (2018) Cervical Cytology: A Review of 597 Cases in a Tertiary Health Centre in Nigeria. Case Reports in Clinical Medicine, 7, 259-268.

https://doi.org/10.4236/crcm.2018.74024

Received: February 18, 2018

Accepted: April 15, 2018

Published: April 18, 2018

Copyright $\odot 2018$ by authors and Scientific Research Publishing Inc. This work is licensed under the Creative Commons Attribution International License (CC BY 4.0).

http://creativecommons.org/licenses/by/4.0/

\begin{abstract}
Background: Cervical cancer is the most common gynaecological cancer among women in the developing countries. It is preventable by early detection and treatment of the precursor lesions. Cervical cytology became the standard screening test for cervical cancer and premalignant lesions with the introduction of the Papanicolau (Pap) smear. Aim: to determine the uptake, indications and results of cervical cytology in a tertiary health center in Nigeria. Materials and Methods: a 5-year descriptive study of the results of cervical cytology among women who attended the gynaecological outpatient clinic of the Hospital. Results: a total of 597 cases of cervical Pap smears were received at the histopathology department during the study period out of which 20 (3.4\%) were inadequate for cytological evaluation. The patients age ranged from 15 to 80 (mean $38.8 \mathrm{SD}=11.4$ ) years. The average annual uptake of the Cervical smear was $9.3 \%$ of the total number of patients seen in the gynaecological clinic during the study period and the main indications were routine medical check-up, 256 (42.9\%) and cervicitis 76 (12.7\%). About 398 (66.7\%) were normal smears while $152(26.3 \%)$ were abnormal. Non-specific inflammatory changes were present in $113(74.3 \%)$ cases. Cytology was positive for intraepithelial lesions in 6.8\% (39/577) cases. Eighteen percent (7/39) of them were high-grade lesions while squamous cell carcinoma was detected in $12.8 \%$ (5/39) cases. Conclusion: the uptake of cervical cytology of $8.7 \%$ is low and the main indication was routine check up. Premalignant lesions were detected in $6.8 \%$ of cases.
\end{abstract}

\section{Keywords}

Cervical Cytology, Cervical Cancer, Nigeria

\section{Introduction}

Cervical cancer is the main cancer among women in sub-Saharan Africa, India, 
and other parts of the developing world [1]. India accounts for a quarter of world's burden of the disease [1]. The country accounted for $23.2 \%(123,000)$ of new global cervical cancer cases and $25.1 \%(67,000)$ of cervical cancer related deaths [2]. Cervical cancer is a leading cause of cancer related death in women in most developing countries of the world and has over 500,000 new cases and more than 300,000 deaths globally each year [3]. It is the second leading cause of cancer-related deaths among women in Jamaica [4]. In Nigeria, cervical cancer accounted for $67.8 \%$ and $77 \%$ of genital tract malignancies in Sokoto and Zaria respectively [5] [6]. Most of the patients present with advanced stages of the disease when treatment for cure is not feasible. This ugly scenario is due to ignorance, poor health seeking behaviour, presence of risk factors such as sexual promiscuity, polygamy, early sexual debut and large number of pregnancies [3] [5]. Similarly, there is no organized screening practice to detect the early forms of the disease. According to the World Health Organization (WHO), the highest burden of cervical cancer occurs in developing nations where there is a lack of effective screening programs and low uptake of Pap smear or pelvic examination [7].

Cervical cancer is preceded by a pre-invasive lesion, which can be detected by exfoliative cytology like a Papanicolau (Pap) smear examination [7]. Therefore, it is considered preventable, as the premalignant stages can be detected cytologically and effective treatment can be offered. The disease is of public health importance, it is common and serious. The natural history of the disease has been known for a long time and it therefore meets the criteria for screening for prevention. Cervical cancer is caused by persistent infection with the oncogenic strains of human papilloma virus (HPV) particularly HPV 16 and 18 [5] [8]. The risk of developing squamous cell carcinoma of the cervix is about 400 times higher following infection with HPV16 and about 250 times higher following infection with HPV18 compared to the risk in uninfected women [9]. The infection is sexually transmitted and is therefore related to lifestyle. Up to $80 \%$ of women acquire the infection in their lifetime [10]. Most of the infection by the virus is cleared by the body defence mechanism, but in about $5 \%-10 \%$ of cases it becomes internalized. It is this persistent infection that results in cervical dysplasia and ultimately cervical cancer. Screening with the conventional Pap smear has been seen to be accompanied by a dramatic reduction in the incidence of cervical cancer in different countries of the world [11]. Cervical cytology became the standard screening test for cervical cancer and premalignant lesions with the introduction of the Papanicolau (Pap smear) in 1941 [12]. The goal of cytological screening is to sample the transformation zone, the area where the physiological transformation from columnar endocervical epithelium to squamous (ectocervical) epithelium takes place and where dysplasia and cancer arise. Well-organized cervical cancer screening programmes have reduced the mortality from cervical cancer by up to $50 \%$ in the developed world [8]. However; in most low-resource countries of the world screening facilities are either absent or rudimentary. Most screening programs are opportunistic, isolated and not pop- 
ulation based. Similarly, the uptake for the Pap test is low even when it is available [13]. Despite these limitations; the conventional Pap smear is still the most widely available screening method for cervical cancer especially in low resource settings. The liquid-based cytology (LBC) aims to minimize errors of omission and commission inherent in the conventional Pap smear. It is now the standard test used by the National Health System (NHS) of the United Kingdom for cervical screening program [11]. However it is yet to take root in many low resource settings. Recently, HPV DNA testing has been recommended by the WHO as a standard screening method for cervical cancer. This is based on the fact that HPV DNA is found in over $95 \%$ of cervical cancers and precursor lesions worldwide [8]. This non-cytological method of screening is not readily available in most centres in Nigeria. Despite the high prevalence of cervical cancer in Nigeria, there is no organized national HPV vaccine immunization programme to provide for primary prevention of the disease. We present the result of a 5-year screening programme for cervical cancer by the conventional Pap smear in tertiary health institution in Nigeria.

\section{Aims and Objectives}

The study aimed to determine the indications, uptake and the results of cervical cytology in a tertiary health institution in Nigeria

\section{Subjects and Methods}

This is a review of all cases of cervical smears that were assessed at the Histopathology department of the hospital over a 5-year period (1st of January 2011 to 31st of December 2015). The smears were from women attending the gynaecological outpatient department and in whom pap was advised by the treating gynaecologist for clinical indications. The hospital is a tertiary health institution located in the region of Nigeria. It has 886 bed spaces and provides tertiary and secondary health care services to neighbouring states. It also runs residency training program for doctors in the various sub-specialists including Surgery, Obstetrics \& Gynaecology, Internal Medicine, Paediatrics, Histopathology among others.

The hospital cases are those referred from health institutions in the metropolis and also from neighbouring states. It also receives referrals from Niger Republic, a country located in the northern frontiers of Nigeria. The study was commenced on the $27^{\text {th }}$ of July 2016 and was completed on the $23^{\text {rd }}$ of October 2016; a period of three months. The Hospital's Research and Ethical Committee (HREC) approved the study (HREC/2016/No.532). The case notes of patients who had Pap smear during the period of study were retrieved from the medical records department. The records were traced to the Histopathology department where the cytology results were extracted and analyzed. Data obtained included the socio-demographics of the patients such as age, parity, place of residence, occupation, indications for cytology, previous cytology, specimen adequacy and results of cytology were recorded in a proforma. Statistical analysis of the col- 
lected data was performed using the SPSS IBM version 20 (IBM version 20.0. Armouk, NY: IBM Corp.). The results were expressed in frequencies, means, percentages, tables, figures and charts. The Bethesda system TBS (2004) with standardized terminologies for reporting cervical cytology was adopted in this study.

\section{Results}

A total of 597 cases of cervical smears were received in the histopathology laboratory during the period of study. About 3.4\% (20/597) were inadequate or unsatisfactory for cytological evaluation according to the Bethesda criteria and were thus discarded. The rest 577 smears were analyzed and thus constituted the study population. The age of the patients ranged from 15 to 80 years with a mean of 38.82 [ $\mathrm{SD}=11.42]$ years. The annual uptake of the Pap smear shows an increasing trend as shown in Table 1. The modal year was in 2013. The average annual uptake of the conventional Pap smear was $9.28 \%$ as shown in Table 1 . Cytology was performed mostly for routine indications in 42.9\% (256/597), cervicitis $12.7 \%$ (76/597), abnormal uterine bleeding (AUB) in $12.1 \%(72 / 597)$, suspected cervical cancer 7.7\% (46/597) while the least indications were post menopausal bleeding (PMB) 3.2\% and utero-vaginal prolapse $2.8 \%$ (17/597) respectively as shown in Table 2. Thus in about $57.1 \%$ (341/597) of cases, the

Table 1. Annual uptake of cervical cytology in relation to overall patient load.

\begin{tabular}{cccc}
\hline Year & $\begin{array}{c}\text { Total no. patients registered in } \\
\text { Gynaecological clinic }\end{array}$ & Number of cervical smears & Annual \% \\
\hline 2011 & 1771 & 18 & 1.0 \\
2012 & 1439 & 124 & 8.6 \\
2013 & 1364 & 190 & 13.9 \\
2014 & 1140 & 115 & 10.1 \\
2015 & 1172 & 150 & 12.8 \\
Total & 6886 & 597 & $\mathbf{9 . 3}$ \\
\hline
\end{tabular}

Table 2. Indications for cervical smear.

\begin{tabular}{ccc}
\hline Indications for Pap smear & Frequency & Percentage \\
\hline Routine & 256 & 42.9 \\
Cervicitis & 76 & 12.7 \\
AUB & 72 & 12.1 \\
PCB & 47 & 7.9 \\
Suspected cervical cancer & 46 & 7.7 \\
Inflammatory & 33 & 5.5 \\
Uterine polyps & 31 & 5.2 \\
PMB & 19 & 3.2 \\
UV prolapse & 17 & 2.8 \\
Total & 597 & 100.0 \\
\hline
\end{tabular}


indication for cytology was due to gynaecological problems.

About $66.7 \%$ (398) of the smears revealed normal findings (NILM) while $26.3 \%(152 / 577)$ were abnormal cytology (including epithelial anomalies, reactive cellular changes of inflammation and infections). Out of the 152 abnormal cases, 113 (74.3\%) were reported to have non-specific inflammatory changes, 16 (10.5\%) showed low grade squamous intraepithelial lesions (LSIL) as in Figure 1, 7 (4.6\%) HSIL (moderate or severe dysplasia) as in Figure 2, while 5 (3.3\%) revealed squamous cell carcinoma (SCC). There were 11 cases of atypical squamous cells out of which 8 (5.3\%) were ASC-US and $3(2 \%)$ were ASC-H as shown in Table 3. The LSIL showed cells with koilocytic changes suggestive of HPV infection and mild dysplasia. Thus cervical intraepithelial cell lesions were observed in 39/577 (6.8\%) of the Pap smears.

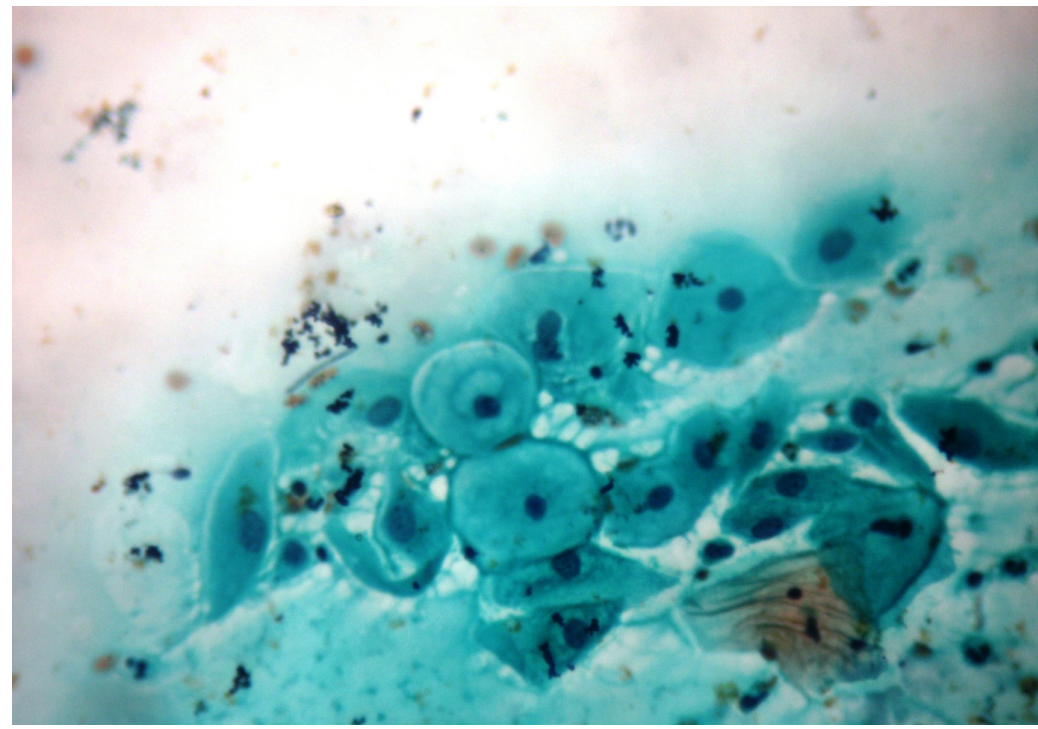

Figure 1. Photomicrograph of low-grade squamous intraepithelial lesion (LSIL).

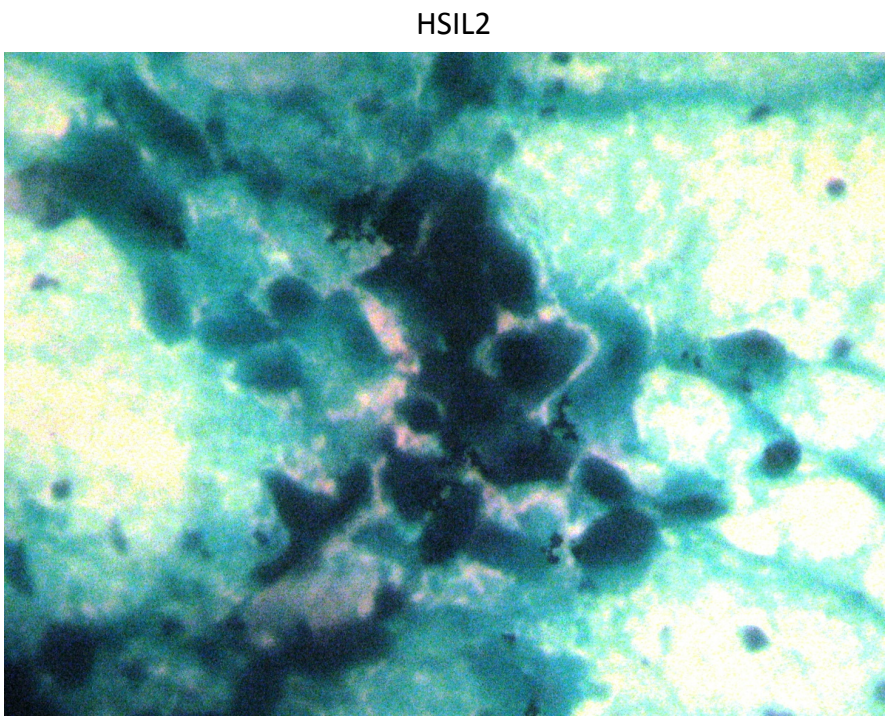

Figure 2. Photomicrograph of high-grade squamous intraepithelial lesion (HSIL). 
Table 3. Cytological diagnosis of pap smears.

\begin{tabular}{ccc}
\hline Cytological diagnosis & Frequency & Percentage \\
\hline NILM & 398 & 66.7 \\
Inflammatory & 113 & 18.9 \\
Atrophic & 27 & 4.5 \\
Inadequate & 20 & 3.4 \\
LSIL & 16 & 2.7 \\
ASC-US & 8 & 1.3 \\
HSIL & 7 & 1.2 \\
SCC & 5 & 0.8 \\
ASC-H & 3 & 0.5 \\
Total & 597 & 100.0 \\
\hline
\end{tabular}

NILM = negative for intraepithelial lesion or malignancy, SCC = squamous cell carcinoma, HSIL = high-grade squamous intra-epithelial lesion, LSIL = low-grade squamous intraepithelial lesion, ASC-US = atypical squamous cell of undetermined significance, ASC-H = atypical squamous cell where high grade lesions could not be excluded.

The maximum number of patients screened in this study i.e. $62.1 \%(371 / 597)$ belonged to the age group of 26 - 45 years followed by $139(23.4 \%)$ patients within the 46 - 65 age range and was least with those in the 7th and 8th decades of life. Many of the cervical smears $28.8 \%$ (172/597) were performed for routine indications in women within the active reproductive age group of 16 - 45 years. This age group is characterized by intense sexual activity, high prevalence of sexually transmitted infections (STIs) including HPV infection, abnormal uterine bleeding (AUB), non-specific inflammation processes and cervicitis as shown in Table 4.

Table 5 showed indications for cytology in relation to cytological diagnosis. Abnormal epithelial changes were observed in 11 (4.6\%) cases of routine cervical smears and 2 out of the 5 cases of invasive carcinoma observed in this study were seen among those who came for routine screening. Table 6 showed that 3 out of the 5 cases of SCC observed in this study were present within the 46 - 55 year age group. Cervical cancer is common within the age range of $40-59$ years with a mean of 55.5 years. Similarly, most of the high grade cytological lesions (6 out of 7) were prevalent within the same age bracket but were absent in patients below the age of 25 years.

\section{Discussion}

The aim of screening for cervical cancer is mainly to detect and treat pre-malignant or pre-invasive lesions before they progress to malignant lesions. In this study, the prevalence of squamous intraepithelial lesion was $6.8 \%$. This is low compared to the $19.8 \%$ observed from previous studies from Sokoto, $12.2 \%$ in Enugu and 9.7\% from Ibadan [13] [14] [15]. Studies carried out on epithelial cell abnormalities in cervical cytology have shown $4.3 \%$ in Kuwait, $7.9 \%$ in Saudi 
Table 4. Indications for pap smear in relation to age.

\begin{tabular}{cccccccccc}
\hline & \multicolumn{7}{c}{ Indications } \\
\cline { 2 - 5 } Age & Routine & AUB & $\begin{array}{c}\text { Vaginal } \\
\text { discharge }\end{array}$ & $\begin{array}{c}\text { Suspected } \\
\text { cervical } \\
\text { cancer }\end{array}$ & $\begin{array}{c}\text { Uterine } \\
\text { polyps }\end{array}$ & Cervicitis & PMB & PCB & $\begin{array}{c}\text { UV } \\
\text { prolapse }\end{array}$ \\
\hline$\leq 15$ & 3 & 2 & 0 & 0 & 0 & 3 & 0 & 1 & 0 \\
$16-25$ & 24 & 5 & 5 & 4 & 0 & 7 & 0 & 8 & 0 \\
$26-35$ & 74 & 21 & 9 & 13 & 6 & 31 & 2 & 16 & 3 \\
$36-45$ & 91 & 26 & 15 & 15 & 17 & 20 & 1 & 14 & 7 \\
$46-55$ & 44 & 15 & 3 & 13 & 7 & 13 & 7 & 8 & 4 \\
$56-65$ & 18 & 1 & 1 & 1 & 1 & 1 & 6 & 0 & 3 \\
$66-75$ & 1 & 1 & 0 & 0 & 0 & 1 & 3 & 0 & 0 \\
$76+$ & 0 & 1 & 0 & 0 & 0 & 0 & 0 & 0 & 0 \\
\hline
\end{tabular}

Table 5. Cytological diagnosis in relation to indication.

\begin{tabular}{ccccccccc}
\hline \multirow{2}{*}{ Indication } & \multicolumn{7}{c}{ Cytological diagnosis } \\
\cline { 2 - 9 } & Normal & Inflammatory & LSIL & HSIL & SCC & ASCH & ASCUS & Atrophic \\
\hline Routine & 194 & 33 & 5 & 2 & 2 & 1 & 1 & 9 \\
AUB & 56 & 6 & 3 & 2 & 1 & 0 & 0 & 3 \\
$\begin{array}{c}\text { Vaginal } \\
\text { discharge }\end{array}$ & 17 & 13 & 1 & 0 & 0 & 0 & 1 & 1 \\
$\begin{array}{c}\text { Suspected } \\
\text { cervical cancer }\end{array}$ & 26 & 12 & 2 & 1 & 2 & 1 & 0 & 2 \\
$\begin{array}{c}\text { Uterine polyps } \\
\text { Cervicitis }\end{array}$ & 24 & 3 & 0 & 0 & 0 & 0 & 0 & 1 \\
PMB & 7 & 31 & 2 & 1 & 0 & 0 & 3 & 3 \\
PCB & 30 & 0 & 2 & 1 & 0 & 1 & 0 & 7 \\
UV Prolapse & 11 & 3 & 0 & 0 & 0 & 0 & 1 & 0 \\
\hline
\end{tabular}

Table 6. Cytological diagnosis in relation to age.

\begin{tabular}{ccccccccc}
\hline \multirow{2}{*}{ Age } & \multicolumn{7}{c}{ Cytological diagnosis } \\
\cline { 2 - 8 } & Normal & Inflammatory & LSIL & HSIL & SCC & ASCH & ASCUS & Atrophy \\
\hline$\leq 15$ & 6 & 3 & 0 & 0 & 0 & 0 & 0 & 0 \\
$16-25$ & 42 & 7 & 2 & 0 & 0 & 0 & 0 & 0 \\
$26-35$ & 125 & 32 & 4 & 1 & 0 & 0 & 4 & 2 \\
$36-45$ & 141 & 43 & 4 & 4 & 1 & 2 & 3 & 2 \\
$46-55$ & 65 & 21 & 5 & 2 & 3 & 1 & 1 & 13 \\
$56-65$ & 14 & 7 & 0 & 0 & 1 & 0 & 0 & 8 \\
$66-75$ & 4 & 0 & 1 & 0 & 0 & 0 & 0 & 1 \\
$76+$ & 0 & 0 & 0 & 0 & 0 & 0 & 0 & 1 \\
\hline
\end{tabular}


Arabia, and 6.8\% in New Delhi India respectively [16] [17] [18]. The worldwide range of positive cytology from the conventional Pap smear is $10 \%$ [19]. The relatively low rate of positive cytology observed in this study could be attributed to the large number of clients $256 / 597$ (42.9\%) that had cytology performed for routine indications and not based on gynaecological symptoms. In the previous study from this centre, most of the indications for cytology were symptom-based (79.4\%), while in Ibadan it was 53.8\% [13] [15]. We also observed from the previous study from this institution that the Pap smear was taken for routine indications in only about $21.5 \%$ of cases, while in this review cytology for routine medical check-up was performed in $42.9 \%$ of patients [13]. Thus, even though the awareness has appreciated, screening for cervical cancer is still opportunistic and not the organized population based.

The annual uptake of the Pap smear showed a rising trend from $1.3 \%$ in the previous study to $9.3 \%$ in this review [13]. This recent increase in the uptake of the conventional Pap smear in our institution could be attributed to the awareness campaign, health education and workshops which were carried out within the hospital complex, places of worship and through the print and electronic media during the periods of 2012 to 2013. Thus, from this study, awareness of the value of cervical cancer screening may have translated to utilization and increase uptake of the Pap smear. This underscores the need for a well-organized population-based national screening programme for cervical cancer.

Chronic cervicitis is a very common condition in adult females and preferentially affects the squamo-columnar junction and the endocervix [18]. It is often accompanied by metaplasia in the epithelium. In this study, we observed that cervicitis was an indication for cervical cytology in $12.7 \%(76 / 597)$ of cases and inflammatory lesions were detected in 20\% (113/577) of cervical cytology. Thus cervical smear examination is a valuable tool in the diagnosis of cervical infections which are very common in women of reproductive age group [18].

Atypical squamous cells of undetermined significance (ASC-US) were observed in $8(1.4 \%)$ of cases in this study. Previous studies have reported the association of ASCUS in a significant proportion of women with Trichomonas vaginalis infection [16] [17]. However this study did not identify any causative organism. A previous review from this centre identified Trichomonas vaginalis in $4 \%$ of the smears [13].

Overall, epithelial cell abnormality of $6.8 \%$ was observed in this study, LSIL was present in $2.8 \%$, ASCUS $1.4 \%$, HSIL $1.2 \%$, squamous cell carcinoma $0.9 \%$ and ASC-H in $0.5 \%$ of cases respectively. In a study of 6173 Pap smears taken for routine screening in Alexandria Egypt, abnormal smears were found in 101 (1.63\%) out of which $0.98 \%$ was diagnosed as ASCUS, ASC-H $0.11 \%$, LSIL $0.10 \%$, while HSIL was present in $0.016 \%$ of cases [20]. The low incidence of cervical intraepithelial lesions and cervical cancer in Egypt was attributed to sexual behaviour, male circumcision, and religious culture [20]. It thus lends credence to the fact that cervical cancer is more prevalent in Africa south of the 
Sahara desert. However, it was also noted that most of the patients with gynaecological symptoms were excluded from participating in the Egyptian study [20].

The major controversy in cervical cancer screening involves the age at which to begin screening (with the Papanicolau smear). In this review, we observed that epithelial cell anomalies were rare in patients below the age of 25 years but became more prevalent thereafter. This is comparable with studies from Egypt [20]. It is thus reasonable to begin screening after the age of 25 years. However, cervical cancer has been detected in women as young as 21 years of age [5]. According to the American Society for Colposcopy and Cervical Pathology (ASCCP), cervical cancer screening should begin at age 21 years [21]. They stated that women under the age of 21 should not be screened regardless of the age of sexual debut or other risk factors. This is because cervical cancer is rare in adolescents and young women and may not be prevented by cytology screening [21]. Cytological abnormalities are common in this age group and can lead to labelling, anxiety, extended surveillance, and invasive procedures such as colposcopy [21].

\section{Conclusion}

In conclusion, this study has observed that the annual uptake of the conventional Pap smear in our institution showed a rising trend, but most of the indications remain symptom based. The presence of epithelial cell abnormalities on cervical cytology is consistent with literature. Awareness of the value of cervical cancer screening could result in increased utilization and uptake of the Pap smear.

\section{References}

[1] Arbyn, M., Sankaranarayanan, R., Muwonge, R., Keita, N., Dolo, A., Mbalawa, C.G., et al. (2008) Pooled Analysis of the Accuracy of Five Cervical Cancer Screening Tests Assessed in Eleven Studies in Africa and India. International Journal of Cancer, 123, 153-160. https://doi.org/10.1002/ijc.23489

[2] GLOBOCAN (2012) http://www.globocan.iarc.fr/Default.aspx

[3] Ferlay, J., Shin, H.R., Bray, F., Forman, D., Mathers, C. and Parkin, D.M. (2010) Estimates of Worldwide Burden of Cancer in 2008: GLOBOCAN 2008. International Journal of Cancer, 127, 2893-2917. https://doi.org/10.1002/ijc.25516

[4] Situational Analysis of Cervical Cancer Prevention and Control in the Caribbean. Pan American Health Organization, 2013.

http://www.who.int/mediacentre/factsheets/fs380/en/

[5] Nnadi, D.C., Singh, S., Ahmed, Y., Siddique, S. and Bilal, Y. (2014) Histo-Pathological Features of Genital Tract Malignancies as Seen in a Tertiary Health Centre in North-Western Nigeria: A 10-Year Review. Annals of Medical and Health Sciences, 4, 213-217. https://doi.org/10.4103/2141-9248.141961

[6] Ifenne, D.I., Shittu, S.O. and Ekwenpu, C.C. (2001) Cervical Smear in Pregnancy: The Zaria Experience. Nigerian Journal of Surgical Research, 3, 81-83. https://doi.org/10.4314/njsr.v3i2.12229

[7] World Health Organization (2014) Human Papillomavirus (HPV) and Cervical Cancer. http://www.who.int/mediacentre/factsheets/fs380/en/ 
[8] Ncube, B., Bey, A., Knight, J., Bessler, P. and Jolly, P.E. (2015) Factors Associated with the Uptake of Cervical Cancer Screening among Women in Portland, Jamaica. North American Journal of Medical Sciences, 7, 104-113. https://doi.org/10.4103/1947-2714.153922

[9] de Sanjose, S., Quint, W.G., Alemany, L., Geraets, D.T., Klaustermeier, J.E., Lloveras, B., et al. (2010) Human Papillomavirus Genotype Attribution in Invasive Cervical Cancer: A Retrospective Cross-Sectional Worldwide Study. The Lancet Oncology, 11, 1048-1056. https://doi.org/10.1016/S1470-2045(10)70230-8

[10] Brown, D.R., Shew, M.L., Qadadri, B., Neptune, N., Vargas, M., Tu, W., et al. (2005) A Longitudinal Study of Genital Human Papillomavirus Infection in a Cohort of Closely Followed Adolescent Women. The Journal of Infectious Diseases, 191, 182-192. https://doi.org/10.1086/426867

[11] Symonds, I.M. (2006) Screening for Gynaecologic Conditions. Current Obstetrics \& Gynaecology, 16, 337-343. https://doi.org/10.1016/j.curobgyn.2006.09.003

[12] Papanicolau, G.N. and Traut, H.F. (1941) The Diagnostic Value of Vaginal Smears in Carcinoma of the Uterus. American Journal of Obstetrics \& Gynecology, 42, 193-206.

[13] Daniel, C.N., Emmanuel, I.N., Lydia, R.A., Arkilla, M. and Sahabi, S.M. (2013) Screening for Cervical Cancer: Experience from a University Hospital in North Western Nigeria (2007-2009). Journal of Basic and Clinical Reproductive, 2, 18-21. https://doi.org/10.4103/2278-960X.112576

[14] Chukwuali, L.I., Onuigbo, W.I. and Mgbor, N.C. (2003) Cervical Cancer Screening in Enugu, Nigeria. Journal of Obstetrics and Gynaecology, 20, 109-112.

[15] Ayinde, A.E., Adwole, I.F. and Babarisa, I.A. (1998) Trends in Cervical Cancer Screening in Ibadan Nigeria: A Four-Year Review. West African Journal of Medicine, 17, 25-30.

[16] Kapila, K., George, S.S., Al-Shaheen, A., Al Ottibi, M.S., Pathan, S.K., Sheikh, Z.A., et al. (2006) Changing Spectrum of Squamous Cell Abnormalities Observed on Papanicolau Smears in Mubaraka Al Kabeer Hospital, Kuwait, over a 13-Year Period. Medical Principles and Practice, 15, 253-259. https://doi.org/10.1159/000092986

[17] Elhakeem, H.A., Al-Ghamdi, A.S. and Al-Maghrabi, J.A. (2005) Cytopathological Pattern of Cervical Pap Smear According to the Bethesda System in Southwestern Saudi Arabia. Saudi Medical Journal, 26, 588-592.

[18] Rana, S., Jairapuri, Z.S. and Jetley, S. (2013) Cervical Smear Cytology on Routine Screening in a Semi Urban Population in New Delhi: A Review of 610 Cases. Archives of Medicine and Health Sciences, 1, 131-135.

https://doi.org/10.4103/2321-4848.123025

[19] Cuzick, J., Jerry, C., Ho, L., Hollingworth, T. and Anderson, M. (1994) Type-Specific Human Papillomavirus DNA in Abnormal Smear as a Predictor of High Grade Cervical Intra-Epithelial Neoplasia. British Journal of Cancer, 69, 167-171. https://doi.org/10.1038/bjc.1994.28

[20] Abdel-Hadi, M., Khalaf, A., Aboulkassem, H., Naeem, N., Baqy, M.A. and Sallam, H. (2015) Cervical Intraepithelial Lesions in Females Attending Women's Health Clinics in Alexandria, Egypt. CytoJournal, 12, 13.

https://doi.org/10.4103/1742-6413.159240

[21] Saslow, D., Solomon, D., Lawson, H.W., Killackey, M., Kulasingam, S.L., Cain, J.M., et al. (2012) American Cancer Society, American Society for Colposcopy and Cervical Pathology, and American Society for Clinical Pathology Screening Guidelines for the Prevention and Early Detection of Cervical Cancer. Journal of Lower Genital Tract Disease, 16, 175-204. https://doi.org/10.1097/LGT.0b013e31824ca9d5 